\title{
The Effect of Testing Temperature on Wear Resistance of Metals Reinforced with Ceramic Particle
}

\author{
Amal Nassar, Eman Nassar \\ Department of Mechanical Engineering, Higher Technological Institute, Tenth of Ramadan City, Egypt \\ *Corresponding Author: eman.nasser@hti.edu.eg
}

Copyright $@ 2013$ Horizon Research Publishing All rights reserved.

\begin{abstract}
The wear resistance of a (A 356) Aluminium alloy reinforced with silicon carbide particles was studied as a function of temperature. The tests were performed at three temperatures $: 5,18$, and $30 \circ \mathrm{C}$, and at three impact loads: 29.4, 39.2 and $49 \mathrm{~N}$ on dray environment. The reductions in the temperature were produced through Conventional cooling unit.The wear rate increased with the increasing in the temperature. The experiments was made also for the same alloy but after reinforced it with $15 \mathrm{wt} . \%$ from silicon carbide particles. The results show that the wear rate of $\mathrm{A}$ $356 / 15$ wt. $\%$ of SiCp were also increases with the increasing in the temperature and with the increasing in the applied.
\end{abstract}

Keywords Wear Rate, Testing Temperature, A356 and $\mathrm{SiCp}$

\section{Introduction}

It is well known that the dispersion of ceramic particles, such as $\mathrm{Al}_{2} \mathrm{O}_{3}$ or $\mathrm{SiC}$ in alloys leads to enhance the stiffness and wear resistance [1-3]. Also, the hard particles reduce moderately the creep rate and the thermal expansion; however the thermal conductivity remains at acceptable levels. This combination of cost and performance is appealing for certain automotive components, where Al-based composites may replace cast iron [4].

Wear word referred to loss in dimension (plastic deformation) if there is an interface between two sliding surfaces. However, plastic deformation such as yield stress is excluded from the wear definition if it doesn't incorporates a relative sliding motion and contact against another surface despite the possibility for material removal, because it then lacks the relative sliding action of another surface. The impact wear is in reality a short sliding motion where two bodies interact for short time interval.[5]

Wear testing is a method for assessing erosion or sideways displacement of material from its "derivative" and original position on a solid surface performed by the action of another surface. This test is commonly used as a simple measure of workability of material in service. Materials behave differently in friction state so it may be important to perform mechanical tests which simulate the condition the material will experience in actual use. Wear testing is typically carried out on the A356 alloy .Fig. 1 shows the microstructure of the A 356 alloy. Wear tests of the selected alloy is a critical parameter for determining the quality of these materials. The loads and forces acting on these materials while in service are compressive in nature and their ability to withstand such loads and forces without failure is a measure of their reliability.[6]

Friction coefficients and wear rates are the most commonly discussed and quantified parameters in tribology. A friction coefficient, $\mu$, is defined as a ratio of the force that resists sliding to the normal force. A tribometer is a device used to measure friction coefficients. While there is no standard tribometry test, experimental setups generally utilize similar design philosophies. In its simplest form, a flat sample is slid against the flat surface of a much larger and harder block of material called the counterface. This results in an approximately uniform pressure distribution within the sample. In many cases, the counterface material and surface finish are important factors in system performance. Upon sliding, the frictional and normal forces are measured or inferred at the specimen simultaneously [7]. A detailed uncertainty analysis of the measurement of friction coefficient on a similar pin-on-flat tribometer was performed by Schmitz et al. [8], and illustrates the metrology challenges associated with such a seemingly simple measurement.

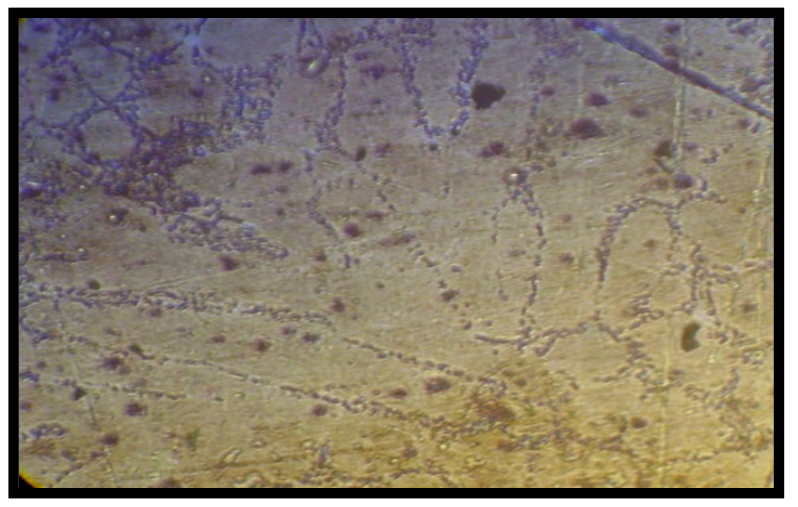

Figure 1. The microstructure of A356alloy (200x). 
The testing temperature is becoming an important factor to be considered in wear and corrosion applications, since ductile-to-brittle transitions in mechanical behavior can affect the mechanisms of mass removal from the surface. At low temperatures, the wear mechanisms are associated to formation of micro-cracks at the surface, which grow leading to material loss in the form of flakes. When the testing temperature is increased, ductile mechanisms like cutting and plastic deformation are favored and the corrosion processes at the surface are intensified [9]. The aim of this work was to analyze the effect of testing temperature on wear resistance of A 356 reinforced with $15 \mathrm{wt} . \%$ from SiC particles.

\section{Experimental Work}

\subsection{Materials}

The materials chosen for the present study was A 356 having the chemical composition shown in table (1). The material was received in the form of bar.

Table 1. Chemical composition of A356

\begin{tabular}{|c|l|l|l|l|l|l|l|l|l|}
\hline \multirow{2}{*}{ From } & \multicolumn{7}{|l|}{ Chemical compositions (wt \%) } \\
\cline { 2 - 10 } & $\mathrm{Si}$ & $\mathrm{Fe}$ & $\mathrm{Cu}$ & $\mathrm{Mg}$ & $\mathrm{Mn}$ & $\mathrm{Ni}$ & $\mathrm{Zn}$ & $\mathrm{Ti}$ & $\mathrm{Al}$ \\
\hline Value & 6.72 & 0.25 & 0.11 & 0.27 & 0.002 & 0.001 & 0.04 & 0.043 & Balance \\
\hline
\end{tabular}

Silicon carbide $(\mathrm{SiC})$ ceramic particles were used as reinforcements in this investigation. The particle having average size of $30-150 \mu \mathrm{m}$, the ceramic having the chemical composition shown in table (2). Fig. (2) Shows A 356 reinforced with 15/wt. from $\mathrm{SiC}$ particles.

Table 2. Chemical composition of $\mathrm{SiCp}$

\begin{tabular}{|c|c|c|c|c|c|c|c|c|}
\hline \multirow{2}{*}{ From } & \multicolumn{7}{|c|}{ Chemical Composition (wt.\%) } \\
\cline { 2 - 9 } & $\mathrm{SiC}$ & $\mathrm{Fe}$ & $\mathrm{SiO}_{2}$ & $\mathrm{Si}$ & $\mathrm{C}$ & $\mathrm{Al}$ & $\mathrm{Ca}$ & $\mathrm{Mg}$ \\
\hline Value & 96 & 0.2 & 0.8 & 0.5 & 0.6 & 0.2 & 0.65 & 1.05 \\
\hline
\end{tabular}

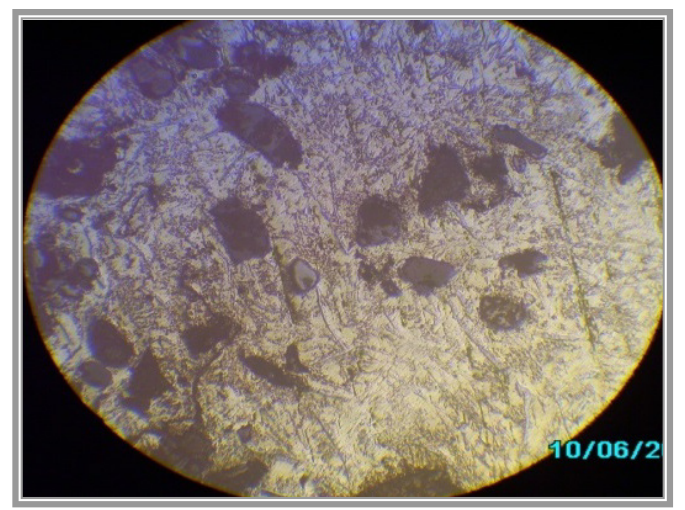

Figure 2. A 356 reinforced with 15/wt from $\mathrm{SiC}$ particles (100x).

\subsection{Wear Test}

The wear test was performed on Pin-on-Disc apparatus shown in figure (3), the design of this apparatus was explained in our previous work [6]. In this test the flat end of Cylindrical specimen $8 \mathrm{~mm}$ in diameter and $12 \mathrm{~mm}$ length was fixed in chuck jaws to prevent specimens from rotation during the test. Axial load was applied to the pins against the plane surface of the rotating disc. The specimen's ends were polished with 1200 grit SiC emery paper and cleaned with acetone. The wear test reported is the average of two readings and was carried out at room temperatures. The standard disc used for testing was made of hard steel ASE 1045 with hardness of 263 BHN whose surface roughness was $0.2 \mu \mathrm{m}$. Table (3) illustrated the Variables combination that used in the investigation. Each specimen was weighed before the experiment and after it by a digital balance having sensitivity of $0.001 \mathrm{gm}$. The duration of the experiment was controlled by digital timer. The average value of the weight loss percentage as a function of test time was calculated. From weight loss of the specimens $(\Delta \mathrm{m})$ it is possible to 
evaluate a dimensional less parameter known as w, "wear rate" define as [10]:

$\mathrm{W}=\frac{\Delta \mathrm{m}}{\rho \times \mathrm{v} \times \mathrm{t} \times \mathrm{A}}$

Where,

$\Delta \mathrm{m}=$ weight loss $(\mathrm{g})$

$\rho=$ average density of material

$\mathrm{t}=$ test time (s)

$\mathrm{A}=$ apparent contact area $\left(\mathrm{mm}^{2}\right)$
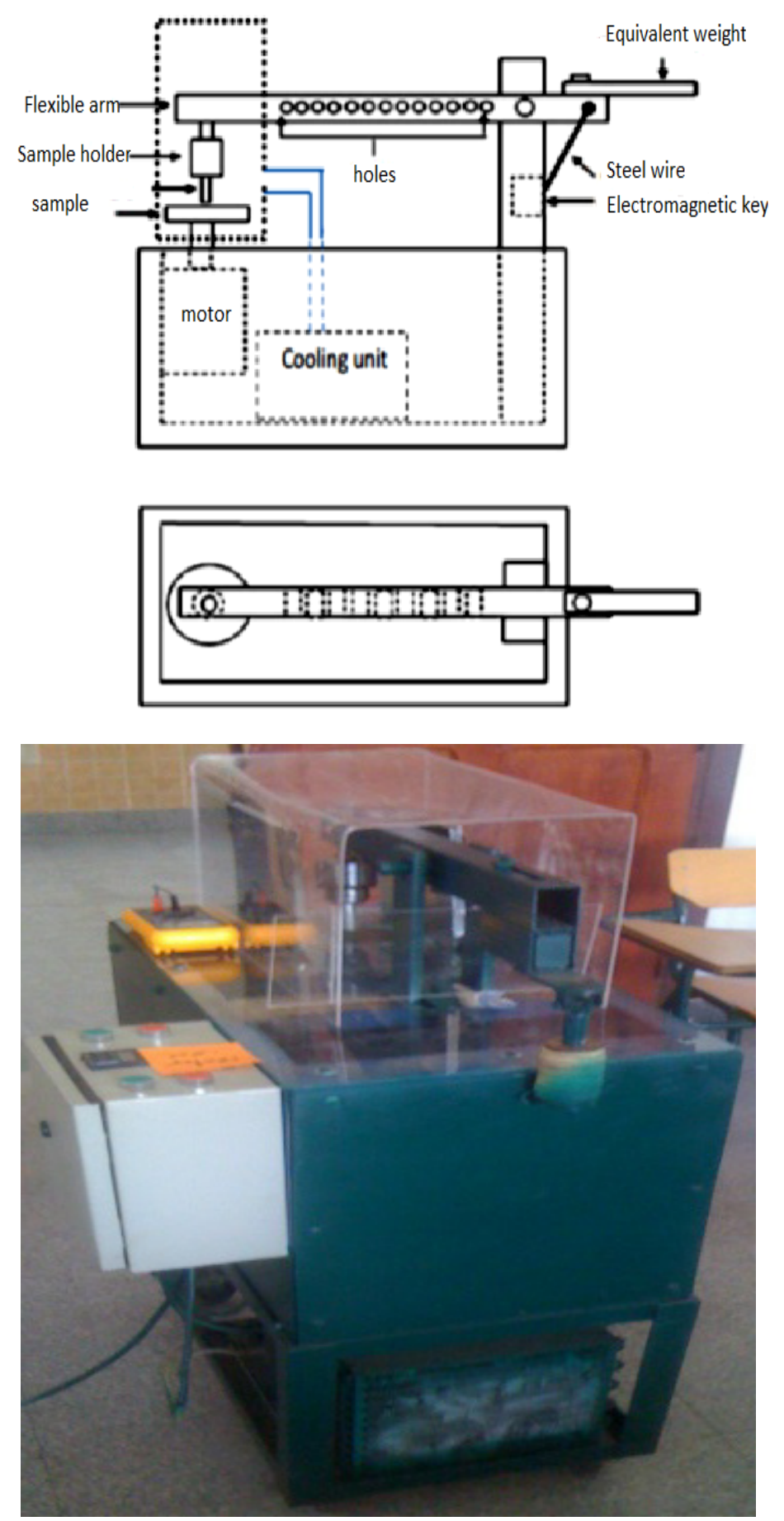

Figure 3. Fabricated wear testing machine 
Table 3. The Variables combination that used in the investigation

\begin{tabular}{|c|c|c|c|}
\hline HIGH & DIAMETER & UNIT & PARAMETER \\
\hline 15 & 8 & $\mathrm{~mm}$ & Pin \\
\hline 20 & 95 & $\mathrm{~mm}$ & Disc \\
\hline \multicolumn{2}{|c|}{1400} & RPM & \multirow{3}{*}{ Disc Rotation } \\
\hline \multicolumn{2}{|c|}{$9.8,19.6$ and 29.4} & $\mathrm{~N}$ & \\
\hline \multicolumn{2}{|c|}{27} & $\mathrm{~mm}$ & \\
\hline \multicolumn{2}{|c|}{13,18 and 30} & $0 \mathrm{C}$ & temperature \\
\hline
\end{tabular}

wight 1 oss after $240 \mathrm{sec}$

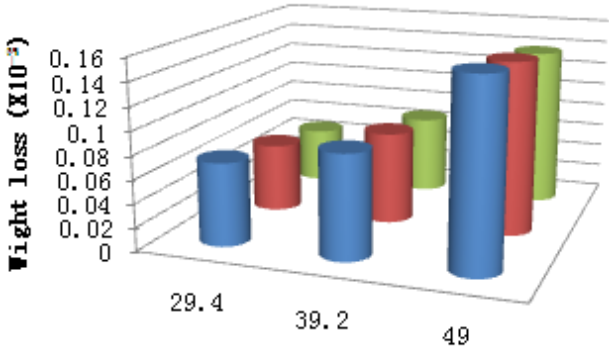

applied load (H)

wight 1 oss after $180 \mathrm{sec}$

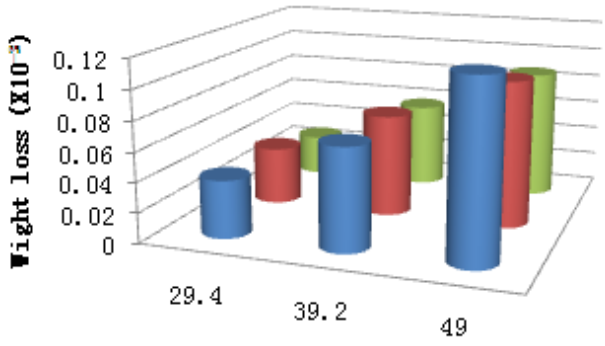

applied load (H)

wight 1 oss after $120 \mathrm{sec}$

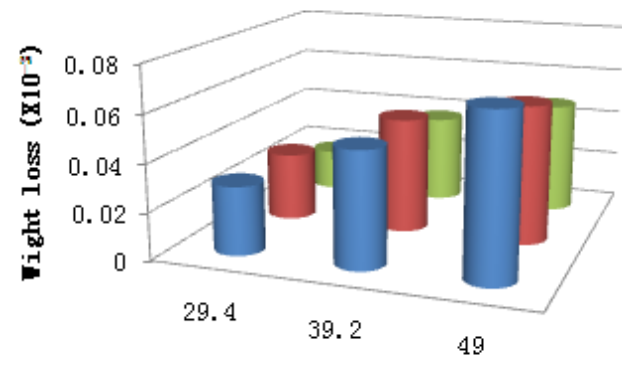

applied load (H)

Figure 4. Wight loss of A 356 at different temperature wight 1 oss after 240 sec.

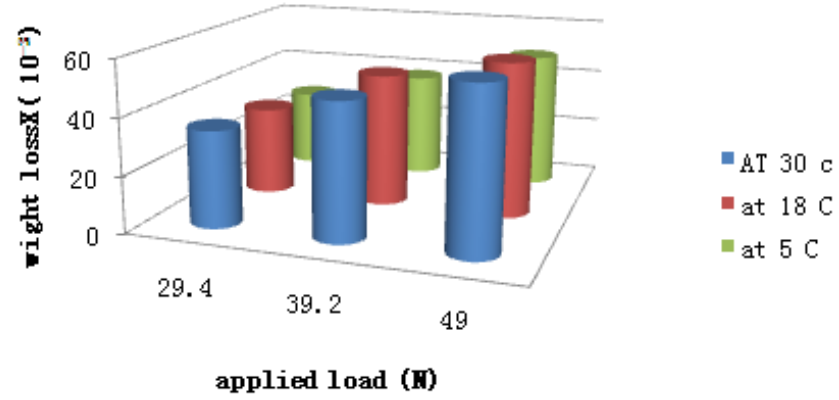

wight 1 oss after $180 \mathrm{sec}$

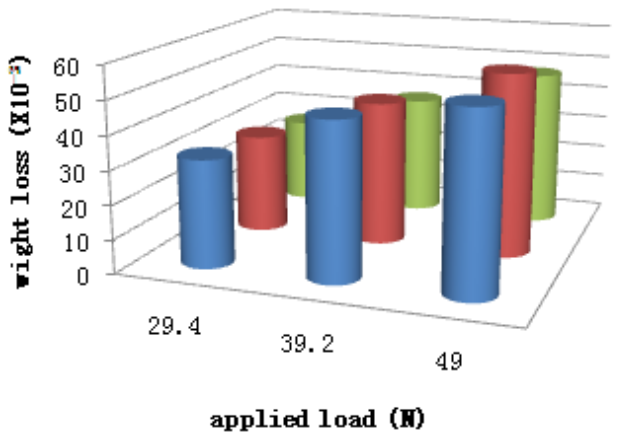

at $30 \mathrm{c}$

at $18 \mathrm{C}$

at $5 \mathrm{C}$

\section{wight 1 oss after $120 \mathrm{sec}$}

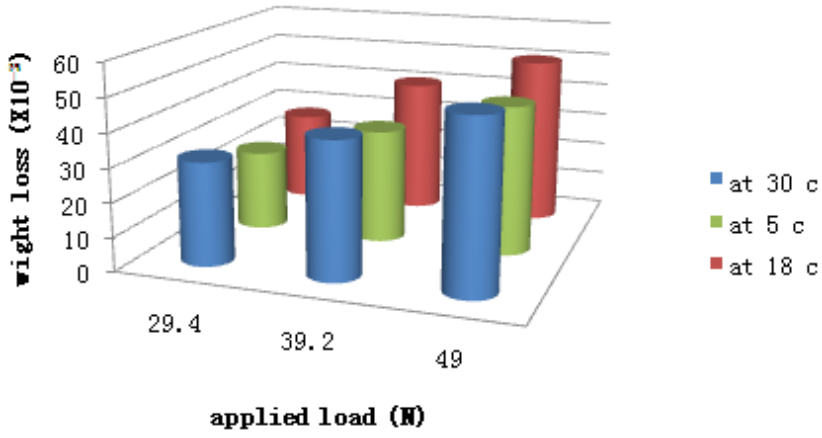

Figure 5. Wight loss of A 356 reinforced with 15/wt from $\mathrm{SiC}$ particles

\section{after $120 \mathrm{sec}$}

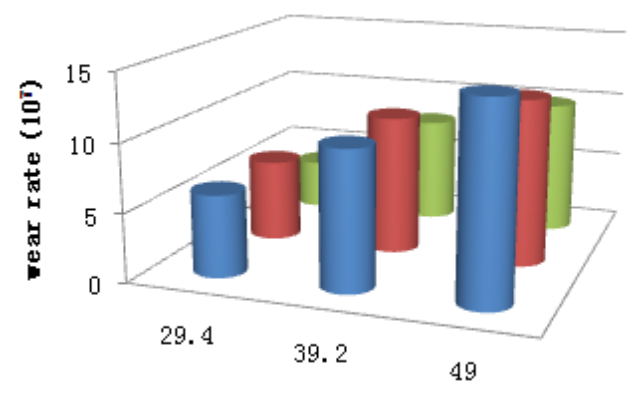

applied load (H) at $30 \mathrm{c}$

- at $18 \mathrm{c}$

at $5 \mathrm{c}$ 


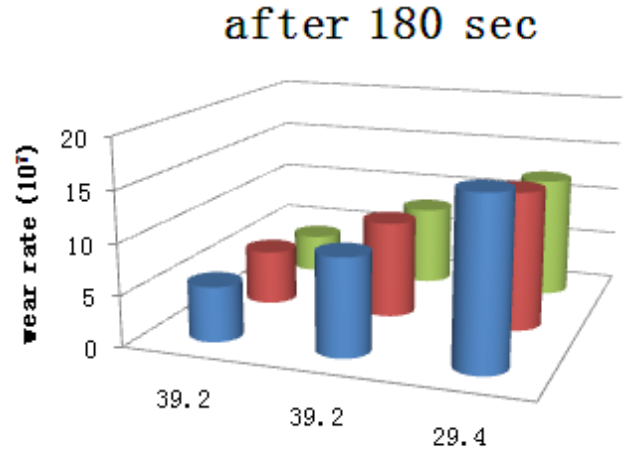

applied load (H)

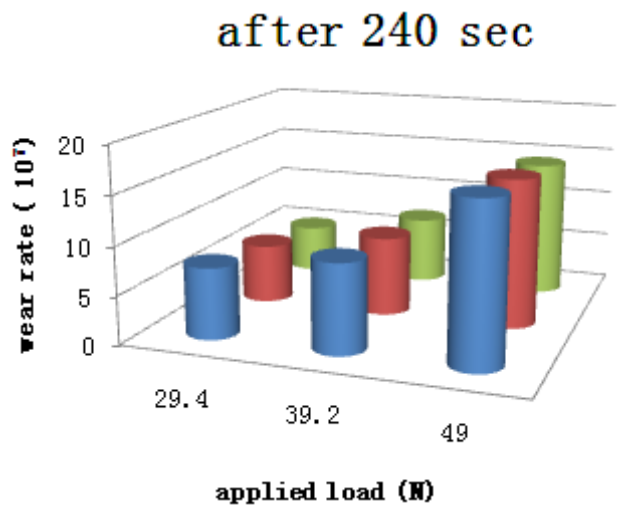

Figure 6. Wear rate of A 356 at different temperatures.
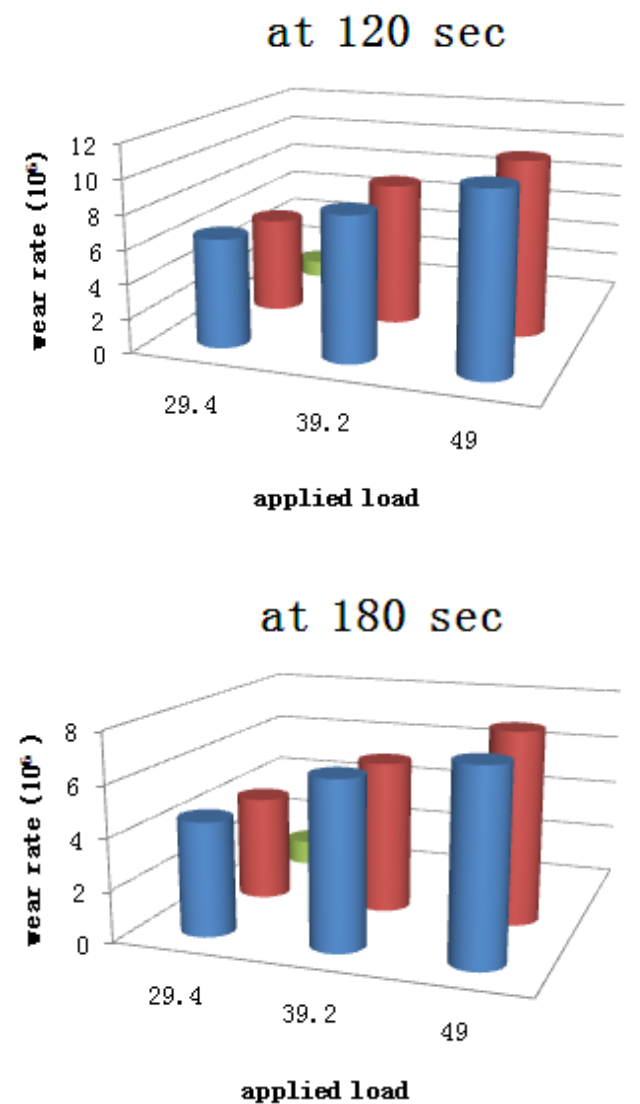

at $240 \mathrm{sec}$

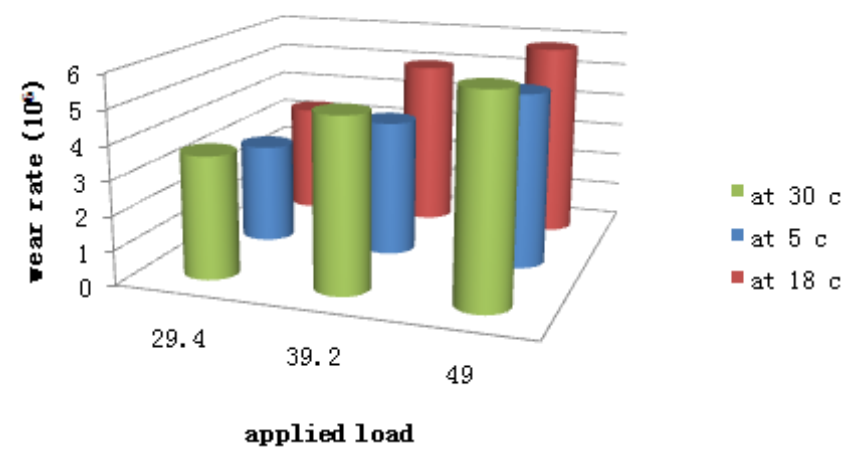

Figure 7. Wear rate of A 356 reinforced with $15 / \mathrm{wt}$ from SiC particles

\section{Results and Discussion}

Figure 4 and 5 show the Wight loss of the studied materials (A 356) as a function of the testing temperatures and different times. Two main features can be seen:

- The wear rate increases as the load increases from 29.4 to $49 \mathrm{~N}$ also, the wear rate decreases as the time increases from 240 to 120 second.

- The wear resistance increases as the temperature decreases from 30 to $5{ }^{\circ} \mathrm{C}$.

Figures also, reveal that increasing in the applied pressure leads to increase the wear rate for all investigated alloys at room temperature.

Figure 6 and 7 show the wear rate of A 356 reinforced with 15/wt. from $\mathrm{SiC}$ particles materials as a function of the testing temperatures. The results show that addition of reinforced particles increases the resistance of the composites to sliding wear under dry conditions, even for small volume fraction of particles. Rohatgi P. Ket. al. [2] in their work report test examination of abrasive wear resistance of Aluminum alloy (A 356) containing fly-ash particles. Their results show that the wear resistance of specimen containing fly ash was comparable to that of alumina fiber-reinforced alloy and superior to that of base A 356 alloy. T. Miyajima and Y. Iwai [10] studied the effect of reinforcements on sliding wear behavior of aluminum matrix composites. Their results show that the degree of improvement of wear resistance of metal matrix composites (MMC) is strongly dependent on the kind of reinforcement as well as its volume fraction. Aluminum metal matrix composites are emerging as promising friction materials. It is generally agreed that the resistance to wear of MMCs is created by reinforcement and higher the volume fraction of particles the better the resistance will be [10-12] however there is an optimum value of the reinforcement which gives maximum wear resistance to the material. The principle tribological parameters that control the friction and wear performances of reinforced aluminum composite can be classified into two categories. One is mechanical and physical factors and the other is material factors [13]. The results also show the effect of testing temperature on the 
weight loss, the wear resistance increases as the temperature decreases from 30 to $5{ }^{\circ} \mathrm{C}$.

\section{Conclusions}

1- Sliding wear tests results of A $356 / \mathrm{SiCp}$ reinforced composites showed that wear rate of composites is greatly lower than the unreinforced A 356.

2- The wear rate decreases as the temperature test decreases from $30^{\circ} \mathrm{C}$ to $5^{\circ} \mathrm{C}$.

\section{REFERENCES}

[1] T. Mochida, M. Taya, D.J. Lloyd, "Fracture of Particles in a Particle/Metal Matrix Composite under Plastic Straining and Its Effect on the Young's Modulus of the Composite," Materials Transactions, JIM, Volume. 32, 2001. pp.931-942.

[2] Rohatgi. P.K., Guo. R.Q., Huang. P., Ray .S., "Friction and Abrasion Resistance of Cast Aluminum Alloy- Flyash Composites", Metal. Mater. Trans. A, Volume .28 A, 1997, pp. 245-250.

[3] Ali Mazahery, Mohsen Ostad Shabani, "A comparative study on abrasive wear behavior of semisolid-liquid processed $\mathrm{Al}-\mathrm{Si}$ matrix reinforced with coated $\mathrm{B} 4 \mathrm{C}$ reinforcement ",Transactions of the Indian Institute of Metals , April 2012, Volume 65, Issue 2, pp 145-154.

[4] Koczak, M. J., Khatri, S. C., Allison, J. E. and Bader, M. G., in Fundamentals of Metal MatrixComposites, ed. S. Suresh, A. Mortensen and A.Needleman. Butterworth-Heinemann, Boston, 1993,pp. 297-326.
[5] Edmond E. Bisson "various modes of wear and their controlling factors". American Society for Testing and Materials San Francisco, 1968, pp.2-4.

[6] Amal E. Nassar and Eman E. Nassar "Design and Fabrication of a Wear Testing Machine", Leonardo Electronic Journal of Practices and Technologies , 2011, pp. 39-48.

[7] David L. Burris, W. Gregory Sawyer "A low friction and ultra-low wear rate PEEK/PTFE composite”. Wear 261 ,2006, pp. $410-418$

[8] Schmitz, T., et al.(2005), "The Difficulty of Measuring Low Friction: Uncertainty Analysis for Friction Coefficient Measurements, "Journal of Tribology-Transactions of the ASME, 127, 3, pp 673-678.

[9] A.P. Tschiptschin, A. Toro," surface properties of High Nitrogen Steels", vdfHochschulverlag, Zurich, 2003, pp. 229-240

[10] T. Miyajima, Y. Iwai., "Effect Of Reinforcements On Sliding Wear Behaviour of Aluminum Matrix Composites" Journal of Wear, Volume. 255, 2003, pp 606- 616.

[11] A. Wang \& H.J. Rack, "Transition wear behavior of SiC-particulate and $\mathrm{SiC}$ whisker reinforced $7091 \mathrm{Al}$ metal matrix composites", Journal of Material Science and Engineering A, Volume. 147, 1991, pp 211-224.

[12] T. Alpas, J. Zhang, "Effect of microstructure (particulate size and volume fraction) and counter face material on the sliding wear resistance of particulate-reinforced aluminum matrix composites", Metall. Mater. Trans. A, Volume. 25, 1994, pp 969-983.

[13] A .P. Sannino, H. J. Rack, "Dry sliding wear of discontinuously reinforced aluminum composite: review and discussion”, Wear, Volume .189, 1995, pp 1-19. 